\title{
Caracterização dos doadores de órgãos e tecidos para transplante do estado do Piauí, de 2000 a 2009
}

Recebido em: 08/12/2010

Aceito em: 14/04/2011
Anna Carollina de Araújo Costa Paz ${ }^{1}$

Priscila Carla de Abreu Ribeiro ${ }^{2}$

Márcio Dênis Medeiros Mascarenhas ${ }^{3}$

Marylane Viana da Silva ${ }^{4}$

A doação de órgãos e tecidos para transplante é um tema permeado por incompreensões e controvérsias. O artigo descreve o perfil clínico-epidemiológico dos doadores de órgãos e tecidos a partir de dados de prontuários de doadores da Central de Transplantes do Piauí de 2000 a 2009 . Dos 308 doadores, predominaram os homens (65,9\%), idade média de 39,2 anos, procedentes do Piauí $(84,7 \%)$. Ocorreram doações de córneas (96,8\%), rim (19,5\%) e coração $(16,6 \%)$. O perfil dos doadores é semelhante aos dados colhidos na literatura específica. Recomendamos a condução de novos estudos e melhorias na rede de transplantes nos níveis municipal e estadual.

Descritores: Doação de Órgãos, Transplantes, Epidemiologia.

\section{Characterization of donor organs and tissues for transplantation in the state of Piauí from 2000 to 2009}

The donation of organs and tissue for transplant is a theme that leads to misunderstandings and controversies. The article describes the clinical and epidemiological profile of organs and tissues donors from donors' files data from the Transplant Center of Piauíf from 2000 to 2009 . Among the 308 donors, males predominated (65.9\%), the mean age was 39.2 years and most of them was from Piauí (84.7\%). There were donations of corneas (96.8\%), kidney (19.5\%) and heart (16.6\%). The donor profile is similar to data from the literature. It is recommended to conduct further studies and improvement in the transplant network at city and state levels.

Descriptors: Organ Donation, Transplantation, Epidemiology.

\section{La caracterización de donantes de órganos y tejidos para transplante en el estado de Piauí, 2000 a 2009}

La donación de órganos y tejidos para trasplante es un tema lleno de malentendidos y controversias. El artículo describe el perfil clínico epidemiológico de donantes de órganos y tejidos a partir de registros de datos de donantes del Centro de Trasplantes de Piauí desde los años 2000 a 2009 . Dentre los 308 donantes, predominan los hombres (65.9\%), con promedio de edad de 39.2 años y procedentes de Piauí (84,7\%). Se han producido donaciones de córnea $(96,8 \%)$, riñón (19,5\%) y corazón (16,6\%). El perfil de donantes es similar a los datos de la literatura específica. Se recomienda la realización de nuevos estudios y mejoras en la red de trasplante en los niveles estatal y municipal.

Descriptores: Donación de Órganos, Trasplantes, Epidemiología.

\section{INTRODUÇÃO}

A doação de órgãos e tecidos para transplante tem sido um tema amplamente discutido em todo o mundo. Entretanto, se por um lado ainda é pouco compreendido pela população em geral, por outro está envolto em diversas e complexas questões que, do ponto de vista político, profissional, econômico e cultural, têm atingido os que necessitam do transplante de órgãos como única possibilidade terapêutica.

No Brasil, a espera por um órgão para transplante ainda é longa, pois a demanda não é suprida pela atual disponibilidade de órgãos doados para efetivação dos transplantes. Contudo, existem experiências exitosas de significativos avanços nessa área no país, a exemplo do estado de São Paulo, onde se registram os maiores índices de doações efetivas com órgãos transplantados ${ }^{(1)}$. Atualmente, o estado do Piauí possui três hospitais credenciados pelo Ministério da Saúde (MS) para realização de processos de transplantes de córneas e de rins.

O processo de doação de rim tem início com a identificação dos potenciais doadores entre pacientes que estejam com suspeita de morte encefálica (ME). Após confirmação do diagnóstico com exames neurológicos e complementares de imagem, os casos são notificados à Central Nacional de Captação e Doação de Órgãos (CNCDO), que, por sua vez, aciona a Organização por Procura de Órgãos (OPO) e Comissão IntraHospitalar de Órgãos e Tecidos (CIHDOTT). Profissionais dessas instâncias realizam avaliação clínica e verificam a viabilidade

1 Acadêmica de Enfermagem, Faculdade Ceut, Teresina-PI. E-mail: carolzinha_paz@hotmail.com.

2 Acadêmica de Enfermagem, Faculdade Ceut, Teresina-PI. E-mail: priiscila.carla@hotmail.com.

3 Doutorando do Programa de Pós-Graduação em Ciências Médicas, Universidade Estadual de Campinas, Campinas-SP. E-mail: marciomascarenhas@ceut.com.br.

4 Mestranda do Programa de Pós-Graduação em Enfermagem da UFPI, Professora da Faculdade Ceut, Teresina-PI. E-mail: marylaneveloso@hotmail.com. 
dos órgãos para transplante, a fim de que a entrevista familiar seja efetivada. Quando há anuência da família, o enfermeiro da OPO colhe amostra de sangue do doador para a realização de exames laboratoriais e informa os dados clínicos desse à CNCDO para que seja identificada a equipe responsável pela retirada e pelo implante dos órgãos ${ }^{(2)}$.

Quanto à doação de córneas, o processo começa ao se identificar um falecido por parada cardiorrespiratória (PCR) durante buscas sistematicamente realizadas por membros da OPO ou CIHDOTT em sua área de abrangência. A seguir, as condições que motivaram o óbito são avaliadas pelos profissionais treinados e inicia-se a entrevista familiar. Mediante a autorização da família, o Banco de Tecidos Oculares (BTOC) é informado, para que haja identificação da equipe para a enucleação do globo ocular, a avaliação e a preservação do tecido e a efetivação da doação(2).

Alguns estudos têm mostrado relativo crescimento no número de transplantes e doações efetivas no Brasil nos últimos anos. Porém, esse incremento ocorreu de forma heterogênea, e ainda existem regiões do país que necessitam de maiores investimentos nessa área terapêutica ${ }^{(1,3)}$.

Este estudo tem por objetivo caracterizar, por meio do levantamento de aspectos clínico-epidemiológicos, os doadores de órgãos e tecidos para transplante no estado do Piauí.

\section{MÉTODO}

Estudo de abordagem quantitativa, exploratório, descritivo, retrospectivo, realizado na $\mathrm{CNCDO} / \mathrm{PI}$, com a utilização de prontuários de doadores cadavéricos de órgãos e tecidos no período de 2000 a 2009. Utilizou-se formulário padronizado, codificado e pré-testado para registrar dados sobre: idade, sexo, raça, procedência, causa do óbito, local de retirada do órgão, confirmação do diagnóstico de $\mathrm{ME}$, resultados de exames sorológicos, órgãos doados e utilizados.

Os dados foram digitalizados com a utilização do software Epi Info 3.5.1. A análise descritiva foi realizada por meio de frequência, percentual e média.

Por se tratar de pesquisa com dados secundários, já registrados em prontuários, solicitou-seoTermo de Autorizaçãolnstitucional, por meio do qual foram asseguradas a confidencialidade e a privacidade, a proteção da imagem e a não-estigmatização dos doadores, garantindo a não-utilização das informações em prejuízo das pessoas e/ou das comunidades, inclusive em termos de autoestima, de prestígio e/ou econômico-financeiro, conforme recomendações da Resolução n 196/1996, projeto aprovado pelo Comitê de Ética em Pesquisa da Universidade Federal do Piauí.

\section{RESULTADOS}

Foram localizados 308 prontuários de doadores cadavéricos na CNCDO/PI, no período de $2000(n=3)$ a 2009 ( $n=99)$. Desses, 246 $(79,9 \%)$ foram submetidos ao protocolo de PCR e $62(20,1 \%)$, ao protocolo de ME. Do total de doações ocorridas no período estudado, $223(72,4 \%)$ resultaram em transplantes efetivos e 85 (27,6\%), em descarte de órgãos e/ou tecidos por não atenderem às condições clínicas ideais para a efetivação do transplante.

Na tabela 1, observam-se as características demográficas dos doadores de órgãos e tecidos incluídos no estudo. Predominaram doadores do sexo masculino $(65,9 \%)$ e com idade média de 39,2 anos ( \pm 16 anos), com maior concentração no grupo etário de 20 a 29 anos $(22,4 \%)$ e de 40 a 49 anos $(21,1 \%)$. Em relação à raça/cor da pele, $77,9 \%$ dos prontuários não apresentavam essa informação. A maioria dos doadores era procedente de municípios piauienses (84,7\%).

$\mathrm{Na}$ análise da variável órgãos ou tecidos doados, o maior percentual foi de córneas (96,8\%), seguidas de rim (19,5\%) e coração $(16,6 \%)$, incluindo os casos de doação múltipla. A análise sorológica mostrou reatividade para doenças infecciosas em 32 doadores, sendo a infecção pelo vírus da hepatite $B$ a mais frequente $(5,2 \%)$ e considerando que havia doadores com sorologia positiva para mais de uma etiologia. Quanto aos doadores com diagnóstico de $\mathrm{ME}$, constatou-se que a confirmação diagnóstica ocorreu por meio dos seguintes procedimentos: teste de apneia (96,8\%), exame neurológico $(95,2 \%)$ e arteriografia $(96,8 \%)$. As doações ocorreram em maior frequência no Instituto de Medicina Legal - IML (33,4\%) e nos dois principais hospitais públicos de Teresina: Hospital Getúlio Vargas (25,3\%) e Hospital de Urgência de Teresina (14,9\%), totalizando $40,2 \%$ de todas as doações (tabela 2).

No que se refere às causas de óbito, destacaram-se as mortes por traumatismo crânio-encefálico $(27,9 \%)$ e acidente vascular cerebral (23,4\%). Aproximadamente $33 \%$ das mortes foram decorrentes de causas que, separadamente, apresentaram menores proporções, entre as quais se destacaram: acidente

Tabela 1 - Características demográficas dos doadores de órgãos e tecidos. Estado do Piauí, 2000-2009

\begin{tabular}{|l|c|c|}
\hline \multicolumn{1}{|c|}{ Características } & N & $\%$ \\
\hline Sexo & & \\
\hline Masculino & 203 & 65,9 \\
\hline Feminino & 105 & 34,1 \\
\hline Faixa etária (anos) & & \\
\hline$\leq 9$ & 4 & 1,3 \\
\hline $10-19$ & 31 & 10,1 \\
\hline $20-29$ & 69 & 22,4 \\
\hline $30-39$ & 46 & 14,9 \\
\hline Sem informação & 1 & 0,3 \\
\hline Raça/cor da pele & & \\
\hline Parda & 40 & 13,0 \\
\hline Branca & 21 & 6,8 \\
\hline Preta & 6 & 1,9 \\
\hline Outros & 1 & 0,3 \\
\hline Sem informação & 240 & 77,9 \\
\hline Total & 308 & 100,0 \\
\hline Fonte: Central de Notificação, Captação e Distribuição de Orgãos do Piaú, $2000-2009$ \\
\hline
\end{tabular}


automobilístico, ferimento por arma branca, aneurisma cerebral, insuficiência respiratória, renal e cardíaca.

\section{DISCUSSÃO}

Os resultados deste estudo apresentam as principais características dos doadores de órgãos do estado do Piauí. Inicialmente, destacase o incremento no número de doações registradas ao longo do decênio estudado.

Com base na literatura sobre a temática doação de órgãos e transplantes, verifica-se que deficiências operacionais, logísticas, econômicas e até político-administrativas podem interferir

Tabela 2 - Características clínicas dos doadores de órgãos e tecidos. Estado do Piauí, 2000-2009

\begin{tabular}{|c|c|c|}
\hline Características & $\mathbf{N}$ & $\%$ \\
\hline \multicolumn{3}{|l|}{ Órgão/tecido disponibilizado } \\
\hline Córneas & 298 & 96,8 \\
\hline Rim & 60 & 19,5 \\
\hline Coração & 51 & 16,6 \\
\hline \multicolumn{3}{|l|}{ Sorologia reagente* } \\
\hline Anti-HBc & 16 & 5,2 \\
\hline HCV & 7 & 2,3 \\
\hline Toxoplasmose & 7 & 2,3 \\
\hline $\mathrm{HBsAg}$ & 4 & 1,3 \\
\hline HTLV & 4 & 1,3 \\
\hline CMV & 3 & 1,0 \\
\hline HIV & 2 & 0,6 \\
\hline \multicolumn{3}{|l|}{ Diagnóstico de morte encefálica** } \\
\hline Apneia & 60 & 96,8 \\
\hline Exame neurológico & 59 & 95,2 \\
\hline Arteriografia & 60 & 96,8 \\
\hline \multicolumn{3}{|l|}{ Local da doação } \\
\hline Instituto Médico Legal & 103 & 33,4 \\
\hline Hospital Getúlio Vargas & 78 & 25,3 \\
\hline Hospital de Urgência de Teresina & 46 & 14,9 \\
\hline Hospital Santa Maria & 40 & 13,0 \\
\hline Aliança Casamater & 24 & 7,8 \\
\hline Prontomed & 5 & 1,6 \\
\hline Hospital da Polícia Militar & 1 & 0,3 \\
\hline Hospital São Marcos & 1 & 0,3 \\
\hline Itacor & 1 & 0,3 \\
\hline Hospital do Matadouro & 1 & 0,3 \\
\hline Sem informação & 8 & 2,6 \\
\hline Total & 308 & 100,0 \\
\hline
\end{tabular}

Fonte: Central de Notificação, Captação e Distribuição de Órgãos do Piauí, 2000-2009

* O mesmo paciente poderia ter mais de um teste sorológico reagente.

** Inclui apenas os casos de morte encefálica. no bom andamento do processo de doação de órgãos, o que, possivelmente, pode ter ocorrido no estado do Piauí(2). No entanto, o ano de 2009 destacou-se por apresentar números significativos, com a efetivação de quase uma centena de doações. Esse fato pode estar relacionado às modificações organizacionais dos serviços de referência em alta complexidade, tanto do manejo técnico nos atendimentos a politraumatizados e vítimas de AVC quanto na organização e implantação do BTOC(4).

Em relação às características demográficas, os resultados encontrados assemelham-se aos verificados na Região Sudeste e no estado da Bahia, onde foi observado predomínio de doadores do gênero masculino ${ }^{(5-7)}$.

Quanto à raça/cor da pele, é importante ressaltar que $77,9 \%$ dos prontuários não apresentaram essa informação. Esse resultado não é congruente com a descrição da contribuição dessa variável no processo de doação de órgãos para o cenário local, haja vista que os estudos preexistentes apresentam conjunturas raciais cuja população branca prevalece nas Regiões Sul e Sudeste, representando $67,1 \%(8,9)$.

No que concerne à faixa etária, as informações encontradas corroboram com aquelas descritas em trabalho anterior, destacando maior frequência entre os indivíduos de 20 a 44 anos $^{(5)}$. Entretanto, no caso de doação de córneas, o limite de idade é bastante relativo, pois os fatores biológicos naturais da idade interferem na qualidade do tecido a ser transplantado. Todavia, em situações de doação de órgãos sólidos, é consenso entre os especialistas que, quanto mais cedo for diagnosticada a ME, melhor será a qualidade do órgão e o sucesso do transplante. Para esses casos, há um tempo máximo permitido para a conservação dos órgãos em isquemia fria para a realização do transplante, sendo que, para o coração, é de quatro a seis horas pós-retirada; o rim, até

Figura 1 - Distribuição proporcional (\%) de doadores de órgãos e tecidos ( $\mathrm{N}=308)$ segundo causa do óbito. Estado do Piauí, 2000-2009

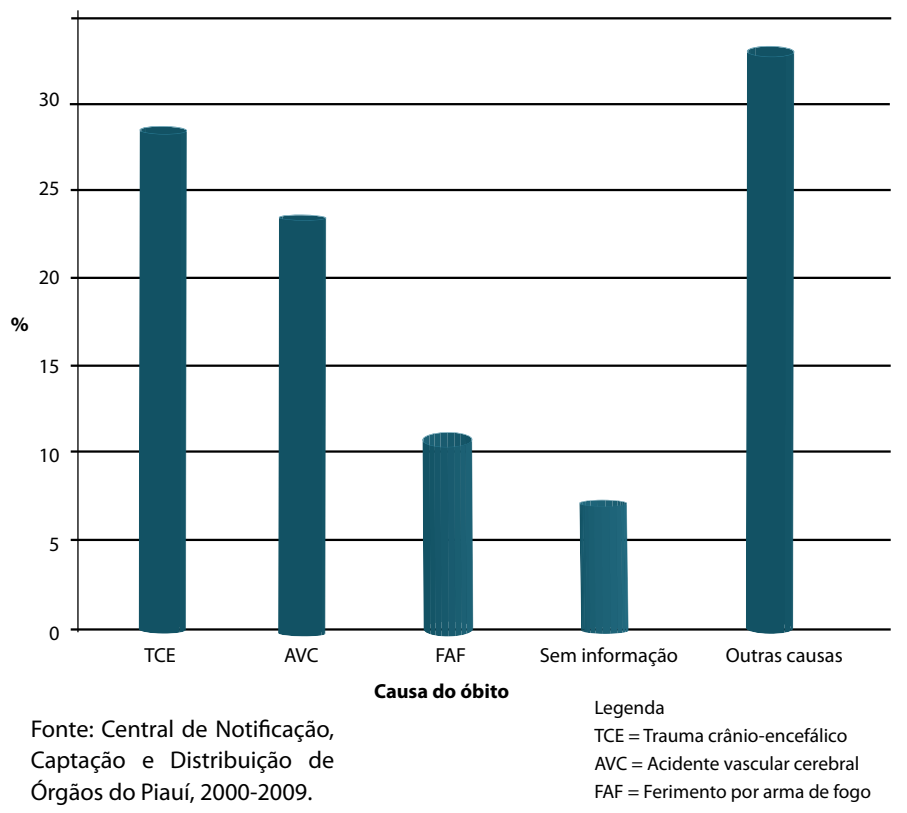


48 horas; e as córneas, de sete a 14 dias, desde que conservadas em solução de optisol à temperatura de $4^{\circ} \mathrm{C}^{(10)}$.

Rotineiramente, os testes sorológicos são solicitados a todos os doadores e, nesse aspecto, $14 \%$ deles confirmaram positividade para alguma doença infecciosa, inviabilizando o órgão para transplante. Contudo, nos doadores que tiveram o protocolo de ME iniciado, além de testes sorológicos, se faz necessária a realização do exame neurológico clínico e um complementar que, nessa realidade, é a arteriografia, realizado em 96,8\% dos doadores, conforme protocolo para ME estabelecido pela Resolução CFM 1480/97, de 8 de agosto de $1997^{(11)}$.

Quanto ao local de ocorrência, o IML oportunizou um terço das doações de córneas, considerando que essas são possíveis nos casos de PCR até seis horas após o óbito. Entretanto, 40,2\% das doações ocorreram em hospitais públicos (HGV, HUT). Esse aumento dos doadores na rede pública deve-se, principalmente, à existência e ao funcionamento das equipes de busca de órgãos (OPO e CIHDOTT, respectivamente), como também pelas características dos serviços.

A rede de atenção à saúde de alta complexidade da cidade de Teresina é referência por sua disposição geográfica e acessibilidade dos municípios fronteiriços dos estados do entorno, tendo em vista seus recursos tecnológicos e humanos. Por isso, predominaram doadores originários do Piauí em detrimento dos poucos casos oriundos do Pará, Ceará e Maranhão, para os quais o tempo de deslocamento e a falta de recursos mais adequados para a resolutividade dos problemas de saúde implicam inúmeros falecimentos, colaborando, portanto, com os resultados encontrados neste estudo ${ }^{(12,13)}$.

Quanto às causas de óbito, o TCE apresentou elevada contribuição para a doação de órgãos e tecidos, relacionado aos acidentes de transporte, especialmente àqueles envolvendo veículos de duas rodas do tipo motocicletas. Esses dados também foram encontrados em estudos retrospectivos, que descreveram o TCE como uma das principais causas de $\mathrm{ME}^{(8,14)}$. Todavia, estudos nacionais recentes não concordam com tais achados por considerarem a faixa etária de maior prevalência entre os 41 e 60 anos, cuja causa de óbito mais frequente foi o AVC entre mulheres, mesmo utilizando metodologia semelhante ${ }^{(3)}$.

Vale ressaltar que outras causas de óbito somam 32,8\% entre o total de mortes, e essa situação permite diversas interpretações, destacando-se que as situações de adoecimento provocadoras de morte lenta e progressiva possibilitam extrema aproximação dos familiares às situações de perda, sofrimento, resignação e até aceitação da morte. Tal circunstância desperta sentimentos e comportamentos de altruísmo humanitário, tornando os parentes mais dispostos à aceitação da doação de órgãos de seu ente querido. Identificou-se que, aproximadamente, $80 \%$ dos doadores tiveram PCR, por isso o maior número de doações de córneas em comparação àquela com diagnóstico de $\mathrm{ME}$, que oportunizaram as doações de órgãos sólidos ${ }^{(5)}$.

\section{CONCLUSÃO}

Conclui-se que houve predominância de homens $(65,9 \%)$, idade média de 39,2 anos, procedentes do Piauí $(84,7 \%)$. Ocorreram significativas doações de córneas $(96,8 \%)$, seguidas, respectivamente, das doações de rim (19,5\%) e coração (16,6\%). O perfil dos doadores mostrou-se semelhante aos dados colhidos na literatura específica.

Este estudo apresenta-se como pioneiro e inédito para o cenário de saúde local, com descrição do perfil da doação de órgãos no estado do Piauí. Tais informações podem contribuir para avaliar e acompanhar o funcionamento, a implantação e a eficiência das ações propostas pela política de transplante no nível estadual.

Reconhecendo que o tema não se esgota no presente estudo, recomenda-se a realização de outros trabalhos que retratem suas questões limitantes, tais como: a manutenção dos potenciais doadores, notificação precoce, análise da qualidade dos registros hospitalares, sobrevida dos transplantados, acompanhamento do processo de morte dos potenciais doadores pelas equipes de busca de órgãos e causas de recusa familiar.

\section{Referências}

1. Associação Brasileira de Transplantes de Órgãos. Registro Brasileiro de

Transplantes. 2010;XVI(4).

2. Ministério da Saúde (BR). Sistema Nacional de Transplantes [Internet]. [citado

em 2010 Abr 02]. Disponível em: http://dtr2001.saude.gov.br/transplantes/

integram.htm.

3. Moraes EL, Silva LBB, Moraes TC, Paixão NCS, Izumi NMS, Guarino AJ. O perfil

dos potenciais doadores de órgãos. Rev Latinoam Enferm. 2009;17(5).

4. Secretaria de Saúde (PI). Piauí agora tem banco de olhos. Teresina: Secretaria

de Saúde; 2009

5. Roza BA. Efeitos do processo de doação de órgãos e tecidos em familiares:

intencionalidade de uma nova doação [tese]. São Paulo: Universidade Federal

de São Paulo; 2005.

6. Reis GAS, Almeida ER, Costa ACP, Silva FMAC. Perfil do potencial doador de órgãos e tecidos no Estado do Rio de Janeiro. X Congresso Brasileiro de Transplantes; 2 a 5 set 2007; Florianópolis: ABTO; 2007.

7.Valverde JG, Santana Jr JSPC, Ferreira MN, Silva IZN, Moura ES. Perfil estatístico da notificação, captação e doação de órgãos no Estado da Bahia. X Congresso Brasileiro de Transplantes; 2 a 5 set 2007; Florianópolis: ABTO; 2007.

8. Moraes EL, Silva LBB, Glezer M, Paixão NCS, Moraes TC. Trauma e doação de

órgãos e tecidos para transplante. J Bras Transpl. 2006;9(3):561-5.

9. Bezerra FD, Carvalho JS. Indicadores socioeconômicos do nordeste. Análise

comparativa inter-regional [Internet]. [citado em 2010 Nov 17]. Disponível

em: http://www.bnb.gov.br/content/aplicacao/etene/etene/docs/analise-

comparativa-egional.pdf.

10. Associação Brasileira de Transplantes de Órgãos. Diretrizes básicas para

captação e retirada de múltiplos órgãos e tecidos. 2009;143.

11. Secretaria de Estado de Saúde (DF). Resolução do Conselho Federal de

Medicina (CFM)1480/97, de 8 de agosto de 1997.

12. Secretaria de Saúde (PI). Hospital Getúlio Vargas: alta modernidade, alta complexidade e alta qualidade. Teresina: Secretaria de Saúde; 2010.

13. Secretaria de Saúde (PI). Hospital Getúlio Vargas: implantará atendimento por classificação de riscos. Teresina: Secretaria de Saúde; 2006.

14. Datasus. Departamento de Informática do SUS - Datasus [Internet]. [citado em 2010 Mar 20]. Avaible from: http://www.datasus.gov.br. 